\title{
Male Neighbors' Behavior: Bystander Effect in Domestic Violence Cases
}

\author{
Nido Dipo Wardana \\ Faculty of Psychology Universitas Airlangga \\ Indonesia \\ nidowardana@gmail.com \\ Margaretha \\ Faculty of PsychologyUniversitas Airlangga \\ Indonesia \\ margaretha@psikologi.unair.ac.id
}

\begin{abstract}
This research was twofold and aimed to explore male neighbors' behavior as bystanders of domestic violence (DV) cases. Study I used survey on 94 male respondents to obtain description about bystander behavior and examine the relationship between situational barriers, neighborhood cohesion, and bystander's intention to help victims. Study 2 used qualitative approach with instrumental case study, involving three male participants to understand the dynamic of bystander effect on male neighbors who had witnessed DV. Bystander effect (BS) is a phenomenon in which individual is less likely to intervene in an emergency if bystander present. BS was analyzed based on three root psychological processes, namely: diffusion of responsibility, audience inhibition, and pluralistic ignorance; the three appeared in the bystander intervention stages. An important finding was the role of neighborhood cohesion which interacted with DV-supporting norm; such that bystanders from highly cohesive neighborhood were resistant to help victims of real DV cases although social cohesion was a notable predictor of intention to help. The evidences in this research expanded Latané's(I98I) theory of social impact as well as supporting Levine (1999) and Banyard and colleagues' (2004) notion of distorted thinking as a root of bystander inaction. Implication of the findings for community-based interventions is discussed.
\end{abstract}

Keywords: bystander effect, domestic violence, male neighbors, neighborhood cohesion.

Received 3 May 2018/Accepted 26 November 2018 @ JEHCP All rights reserved

\section{Introduction}

American Psychological Association or APA (Walker, 1999) defined domestic violence (DV) as a pattern of abusive behavior-physical, sexual, or psychological-in an intimate relationship to obtain or to maintain authority misuse. DV occurred in every nation in the world(Walker, 1999). In Indonesia, Act no. 23 of 20I4, which regulates the elimination of DV, prioritizes violence against woman. Many studies indeed showed that domestic violence against woman was more frequent than it was against man (McQuigg, 20II). 
The United Nation (UN) predicted that $20 \%$ to $50 \%$ woman in the world experienced physical abuse by their partner or family member (Kimmel, 2002). Meanwhile, World Health Organization(2013) noted that almost third of woman in the world was abused by their intimate partners. In Indonesia, 5,784 cases of violence against wife occurred in 2016 and 6,725 cases in 2015(National Commission on Violence against Women, 2016, 2017). Furthermore, in Surabaya, police records had noted I32 DV cases in 2013, I3I cases in 2014, and III cases in 2015 (Unit PPA Satreskrim Polrestabes Surabaya, 2015). Researchers from Universitas Airlangga, Indonesia also found 62 DV cases from Surabaya and Sidoarjo police record in 20II, indicating that DV has long been an issue of concern in East Java, particularly Surabaya(Margaretha, Nuringtyas, \& Rachim, 20I3). However, these recorded cases were simply an iceberg phenomenon. It means that many cases of violence against woman were not yet uncovered(National Commission on Violence against Women, 2016, 2017).

Indonesian National Commission on Violence against Women (2017) also noted that only94.8\% of the reported cases had been completely, legally processed. Referring to another report by LBH APIK Jakarta (20II), only 140 out of 706 reported cases in $201 \mathrm{I}$ had been given legal assistance. This evidence certainly indicated defective service for the reporting of DV, aside from survivor's low awareness (due to lack of knowledge or social barriers) to report it. LBH APIK Jakarta (20II) elaborated that this condition was due to some obstacles woman survivor must deal with while reporting the violence, e.g. perpetrator's report was being prioritized, perplexing, and discriminative law enforcement bureaucracy, and the procedural inconsistence carried out by officers with the Act of Elimination of DV. If these circumstances constantly occurred, it would discourage or frighten woman victim to report the abuse they went through. It would also sustain the DV. Thus, a strategy to boost victim's reporting is tremendously necessary.

Not only legal process, but internal condition (i.e. anxiety pertaining social sanction) of the victim themselves also prevents them to report DV. Berk, Berk, Newton, and Loseke (1984) found that $14.4 \%$ of victim participants in their research were afraid that they would be scorned by their friends and neighbors if they reported DV to the police. They also identified that the presence of bystanders (i.e. friends and neighbors) at the scene of DV provided support for the victims and encouraged them to report. Such role of the community member as friends and neighbors should be used to help victims report the violence they suffered. 
Community member can play role as witness or bystander of DV. Bystander is defined as individuals involved in oppressive incidents, but are neither perpetrator nor victim (Katz, 2006). Inasmuch as every human's suffering involves bystanders (Levy \& Ben-David, 20I5), community members are very potential to be one, including in the case of DV. This role as potential bystander should be empowered to prevent and to eliminate DV. In many studies of sexual abuse, the effectiveness of bystander approach-based prevention has been widely examined (Banyard, Moynihan, \& Plante, 2007). The same thing should also be applied in the studies concerning DV. This involvement of community member in DV elimination is actually ratified in Act no. 23 of 2014. Unfortunately, in Surabaya, victims generally reported the DV on their own without any company of their relatives (Brigadir Andini Putri [Surabaya police officer], personal communication December 2lst, 2015). This fact somewhat described the dearth of community member's participation as active bystander in Surabaya, although more valid data concerning this matter is not yet available.

Specifically, the role of men as bystander of DV holds a great contribution (Katz, 2006). Social pressure to conform, tolerant against violence, and violence against women as a taboo subject (i.e. speaking about men's violence against women makes a man questionable in term of their machismo and sexuality, as if they become more feminine and gay) among men reinforce and help sustaining violent behavior toward women, as well as encourages men to silence about it (Flood, 20l la; Katz, 2006; Schwartz \& DeKeseredy, 2008). Masculinity in men can also inhibit prosocial behavior, such as individuals with strong masculinity tend to be anticipatorily anxious about embarrassment which may result from intervening ambiguous situation(Tice \& Baumeister, 1985). In addition, a study by Rich, Utley, Janke, and Moldoveanu (2010) found that men failed to understand their contribution and responsibility to help in cases of violence against women, because men endorsed masculinity value which actually marginalizes woman's social role and reinforces rigid gender role separation. Another study found that only $I$ in 4 people calling the police to report DV cases was male (Hoefnagels \& Zwikker, 200I). Male was also found to be more endorsing of general rape myth and less willing to help in term of sexual assault cases (Banyard et al., 2007). This might occur because men were less sensitive toward cues of violence or might simply support the idea that men are less willing to take part in violence against women intervention. Thus, studies about DV should focus on 
men's behavior, rather than on women's (Katz, 2006; Schwartz \& DeKeseredy, 2008), because if only few men are willing to participate, DV will never stop occurring (Katz, 2006).

However, previous research proved that men could benefit from bystander-based rape prevention program and became more willing to be active bystanders (Banyard et al., 2007; LanghinrichsenRohling, Foubert, Brasfield, Hill, \& Shelley-Tremblay, 20II). The effectivity of such program might result from the nature of bystander approach which place man as a potential bystander of violence instead of a potential assailant; hence male participants are less defensive against and more engaged with the program. In addition, bystander-based intervention also focuses on attitude toward violence against women which is amenable to change. Positive attitudinal change had been found to correlate with better knowledge about sexual violence and risky dating behaviors (Banyard et al., 2004). These findings suggest that distorted thinking, including distorted belief, norms, or value, is the critical factor that should be addressed in bystander intervention.

The role of men in violence against women is even more salient when patriarchy is taken into account (Katz, 2006). Researchers had addressed patriarchy, among other causes, as the main cause of violence against women ( $\mathrm{Xu}$ \& Anderson, 2010). In particular, patriarchy is a strong characteristic of Asian culture (Xu \& Anderson, 2010). Particularly, in Indonesia, the gender role attributed to women comprises compliance to men and acceptance of violence as a part of their daily lives. Therefore, Asian culture tends to have a higher tolerance regarding the use of violence.

Aside from cultural factor mentioned above, one particular social psychological phenomenon can also hinder bystander intervention, which is called bystander effect. Bystander effect is a condition in which social norm to intervene is attenuated by the presence of other bystanders, either real or imagined presence, thus it lessens the likeliness to help(Darley \& Latané, 1968; Garcia, Weaver, Moskowitz, \& Darley, 2002). This effect may lead bystander to silence and fail to provide any aid.

Many studies attempted to explore factors causing bystander effect. After a series of study on bystander effect, Darley and Latané (Latané \& Nida, 198I) proposed three psychological processes precipitating it, namely: (I) Diffusion of responsibility, i.e. a condition in which responsibility to help is diffused to all bystanders present at the scene, hence it lessens the perceived personal responsibility to provide aids (Darley \& Latané, 1968); (2) Audience inhibition, i.e. perception that 
helping behavior can lead to embarrassment, so the presence of other bystanders increases the risk of embarrassment (Darley \& Latané, 1968); (3) Pluralistic ignorance (i.e. a kind of social influence) is a tendency to rely on other's overt reaction when trying to recognize an ambiguous situation, thus one's likely to be unresponsive if other bystanders seem passive as well (Baron \& Branscombe, 2012; Darley \& Latané, 1968; Fischer et al., 20I I).

Furthermore, Latané and Darley (Baron \& Branscombe, 2012; Fischer et al., 20I I; Latané \& Nida, 198I)also coined an assumption that bystander's prosocial behavior is determined by a series of decisions which bystander needs to take quickly at an emergency situation. Based on this notion, they built a theoretical model of psychological stages of bystander intervention. They postulated five stages which bystanders must undergo before they eventually decide to intervene an emergency, namely (I) Noticing; (2) Interpreting; (3) Taking responsibility; (4) Deciding to help; and (5) Providing help (Baron \& Branscombe, 2012; Suryanto, Putra, Herdiana, \& Alfian, 20I2).In every stage, there is certain decision which bystander should take. Failure to make a decision to help in one stage will lead to unresponsiveness toward the emergency nature of DV.

In addition to situational factors, cohesion also plays role in bystander behavior. Cohesion isthe degree of attraction between members of a group that share the same goals and their interdependence in achieving the group's productivity (Suryanto et al., 2012, p. 290). In a neighborhood, there are three dimensions shaping neighborhood cohesion: sense of community, degree of attraction, and degree of interaction (Buckner, 1988). Cohesion itself is associated with bystander effect. A research by Rutkwoski, Gruder, and Romer (1983) illustrated that group cohesion could reverse bystander effect (i.e. number of bystanders increased the possibility of intervention). Further, it found that facilitation of helping behavior was more likely to take place in a cohesive group which shared salient norm of social responsibility.

Rutkowski and associates' research, however, was conducted in western culture. Only few studies had covered cohesion in its relation with bystander effect in Indonesia. Whilst in fact, Indonesia is a country with a high collectivistic culture which is characterized with a strong cohesion (Hofstede, Hofstede, \& Minkov, 2010). Therefore, the cohesion of Indonesian community should be a principal component in exploring bystander effect. 
Unfortunately, bystander effect has yet been widely studied in DV cases. As Hoefnagels and Zwikker (200I) stated, studies about bystander behavior are fairly limited to outdoor violence such as sexual assault and rape, meanwhile empirical knowledge about bystander behavior in indoor violence cases like DV often receives generalization from rape studies. A survey by Hoefnagels and Zwikker (200I) was one of the first study to use bystander approach in DV cases. They found that most report about DV cases was delivered by woman and children or adolescent under 20 years old. Later study examined factors affecting bystander behavior and found some which hold significant impact on bystander intervention such as personal responsibility, severity of the incident, and sex (Gracia, García, \& Lila, 2009); sex, experience of child abuse, and aggressiveness (Chabot, Tracy, Manning, \& Poisson, 2009); attitude toward violence against women and self-efficacy (Lazarus \& Signal, 2013). Other studies focused on examining the effectivity of bystander-based intervention program and found that some programs were not scientifically anchored (Cismaru, Jensen, \& Lavack, 2010), while some others were proved to be effective in enhancing bystander intervention (Banyard et al., 2007; Langhinrichsen-Rohling et al., 20II). However, most of those researchers only measured the bystander intention or willingness to intervene a hypothetical case without examining actual bystander behavior in real cases.

This research is twofold and aims to mend the knowledge gap left by previous studies. The two parts of this research used different approaches, but both focused on male neighbors' behavior as bystander of DV cases.

\section{Study 1}

The first study attempted to obtain description about male neighbors' behavior, as either actual bystander or potential bystander of DV cases. We operationalize bystander behavior as bystander intention to help and their perceived situational barriers to help victim of DV. This study explored their relation to demographic factors and cohesion. As mentioned before, such data on bystander behavior in Indonesia is hardly available despite the fact that the number of DV cases in Surabaya in particular, and in Indonesia in general, is high. This study was quantitative and used survey in data collection process. 


\section{Study 2}

The second part of this research aimed to explore the dynamics of bystander effect on male neighbors who witnessed domestic violence. This study applied qualitative approach with instrumental study case using Latané and Darley's situational model of helping behavior (Burn, 2009) as its theoretical perspective. Qualitative approach was chosen to obtain in-depth insight on how various social and psychological factors could affect male neighbor's decision to help and lead to bystander effect phenomenon in the context of DV which was hardly tapped in prior quantitative studies. Based on the theoretical perspective, male neighbors will experience bystander effect if diffusion of responsibility, audience inhibition, or pluralistic ignorance is present, as well as barriers in their stages of intervention. The effect of neighborhood cohesion in bystander effect was also examined in the current research.

\section{Method}

\section{Study 1}

\section{Participants}

Ninety-four (94) male respondents were involved in this study and were recruited from one urban area in Surabaya, Indonesia through accidental sampling. The age of participants ranged from 22 to 40 years old $(\bar{x}=3.3$, SD $=5.39)$. The majority of participants was Javanese $(95.7 \%)$ and came from lower-middle socioeconomic class (i.e. $59.6 \%$ only had high school background and $50 \%$ earned 2.5-5 million rupiahs (I75-350 US\$) a month). The respondents comprised actual bystanders (i.e. those who had experience of witnessing DV cases) $(24.5 \%)$ and potential bystanders (i.e. those who had never witnessed DV cases) (75.5\%).

\section{Measures}

Demographic Questionnaire.

A questionnaire was used to collect data concerning respondents' demographics. The demographic data included age, ethnicity, educational background, monthly income, and experience of witnessing DV case. 


\section{Situational Barriers Scale}

The first measure used in this study was situational barriers scale. This scale was constructed based on the theoretical indicators provided by Burn's (2009) Barrier Scale which was also anchored to Darley and Latané's situational model. It consisted of 17 items and used 7-points Likert scaling $(\mathrm{I}=$ strongly disagree, $4=$ neutral, $7=$ strongly agree) to measure perceived barriers in all five bystander intervention stages. Items include statements about situational barriers in the noticing stage ("Conditions at my home made it difficult for me to notice if something happens outside"), the responsibility taking stage ("If I saw someone I didn't know became a DV victim, I would leave it up to his/her neighbors to intervene"), to the help providing stage ("Even if I thought it was my responsibility to help my neighbor from being a DV victim, I might not out of concern I would look foolish"). Trial test of the scale to 39 online respondents resulted in Alpha reliability $\alpha=0.76$. It had also been reviewed by three experts to ensure validity of the test content.

\section{Intent to Help Neighbors Scale}

This scale was adapted from Intent to Help Friends scale developed by Banyard, Moynihan, Cares, and Warner (20I4). It was composed of 10 items using 5-points Likert scaling ( 1 = very unlikely, 3 = neutral, 5 = very likely) measuring intention to help neighbors from DV-related situations (e.g. "I approach my neighbor if I thought they experience DV and let them know that I'm here to help", "If I see my neighbor talking to his wife/her husband who looks scared, I would ask them if they are okay", "I approach my neighbor who looks in pain when they're forced to get into their house by her husband/his wife"). It obtained Alpha reliability of $\alpha=0.82$ in the trial test. Three experts had reviewed the validity of its content.

\section{Neighborhood Cohesion Scale}

This scale was adapted from Neighborhood Cohesion Instrument by Buckner (1988). It was made up of 18 items using 5-points Likert scaling ( $I=$ strongly disagree, $3=$ neutral, $5=$ strongly agree). This scale comprises three dimensions, namely attraction-to-neighborhood (e.g. "Overall, I am very attracted to living in this neighborhood"), degree of neighboring (e.g. "I visit with my neighbors in their homes"), and psychological sense of community (e.g. "I feel like I belong to this neighborhood"). Its reliability based on the trial test's result was $\alpha=0,876$. The validity of the content of this scale had been assessed by three experts. 
Data Analysis

This study used t-test, ANOVA, and multiple regression to analyze the quantitative data. The t-test and ANOVA were conducted to investigate score difference in situational barriers, intention to help victims, and neighborhood cohesion across groups based on demographic characteristics. Meanwhile, multiple regression analysis was run to examine the influence of situational barriers and neighborhood cohesion on respondents' willingness to help DV victims.

\section{Study 2}

\section{Participants}

The second study involved three male participants from the community who had witnessed DV and did not intervene at the given incident. Community samples were used because they represent the actual phenomenon of bystander effect on DV cases in Indonesia. The samples were selected because they were not the only witness at DV scene, but also taking part in bystander effect as a socio-psychological phenomenon in their community. Male witnesses were focused, so this study can explain the impact of the interaction between being male witness with knowing that the perpetrator of DV are mostly males on bystander effect. This study collected the participants through a survey which results in several candidates for participant. The three consenting participants were chosen due to the fact that they had witnessed the incident directly (as opposed to knowing the incident from hearsay) within the past 2 years from when the interview was conducted as it allows participants to recall their experience vividly. All participants came from different neighborhood but within the same urban area in Surabaya. The neighborhoods shared similar stereotype. Outsider tend to see the neighborhood as a somewhat hostile environment due to some antisocial drinking and thievery that happened in the past, even though participants stated only few crimes had occurred in the neighborhood recently. Participant I (KD), aged 38 years old, and served as security staff in his neighborhood. He had lived in that neighborhood for 15 years. Then participant 2 was AY, 40 years old. He had lived in his neighborhood for 20 years and had once served as vice chief of RT (Rukun Tetangga/neighborhood). Meanwhile, participant 3 was named HG, aged 29 years old, and had never held any authority position in the neighborhood. He had lived there since his childhood. 


\section{Procedures}

Participants were recruited during a survey of study I. Researchers also consulted with local authorities of the area (i.e. chief of RT) to obtain suitable participants. Prior to interview, researchers approached each participant individually to inform about the research and obtain a written consent. This procedure was done at least two weeks before the in-depth interview. Then, the interview was conducted in participants' respective houses with a male interviewer.

The in-depth interview used general guideline approach, in which the researchers made a list of questions in advanced (Patton, 2002). In this study, the guideline was constructed based on the theoretical perspective. It had also been evaluated by three experts prior to the in-depth interview. The guidelines include question about participant's identity and history (e.g. "How long have you been living in this neighborhood?"), situational barriers in each stage of intervention (e.g. "Did you think that there is particular person(s) who should intervene the scene?"), neighborhood cohesion (e.g. "Do you feel close with your neighbors?"), and other neighborhood-related question (e.g. "Is there any security issue here in this neighborhood?").

\section{Data Analysis}

This study used a theory-driven thematic analysis to draw significant themes from the qualitative data. To do this, recording of the in-depth interviews was first transformed into verbatim transcripts. Researchers then paraphrased and synthesized the main topics in the transcripts. Syntheses were compared with the theoretical perspective to find out to which part of theoretical framework each synthesis belong to.

\section{Result}

\section{Result of Study I}

Demographics.

The descriptive of perceived situational barriers, neighborhood cohesion, and intent to help neighbors scores can be seen in Table I. Overall, the three scores tended to be negatively skewed and leptokurtic. However, only respondents' score in neighborhood cohesion is significantly skewed and leptokurtic $(p<.05)$. 
Table I

Bystander Behaviour and Neighbourhood Cohesion across Demographic Groups

\begin{tabular}{|c|c|c|c|c|c|c|c|c|c|c|c|c|}
\hline \multirow[t]{2}{*}{ Demographic Variables } & \multicolumn{4}{|c|}{ Perceived Situational Barriers } & \multicolumn{4}{|c|}{ Neighbourhood Cohesion } & \multicolumn{4}{|c|}{$\begin{array}{l}\text { Intent to Help } \\
\text { Neighbours }\end{array}$} \\
\hline & $t / F$ & & $\mathrm{df}$ & $r / \omega^{2}$ & $t / F$ & & $\mathrm{df}$ & $r / \omega^{2}$ & $\mathrm{t} / \mathrm{F}$ & & df & $r / \omega^{2}$ \\
\hline Mean (S.E.) & \multicolumn{4}{|c|}{$61.81(1.48)$} & \multicolumn{4}{|c|}{$72.09(1.09)$} & \multicolumn{4}{|c|}{$33.39(.82)$} \\
\hline Standard Deviation & \multicolumn{4}{|c|}{14.33} & \multicolumn{4}{|c|}{10.52} & \multicolumn{4}{|c|}{7.94} \\
\hline Skewness (S.E.) & \multicolumn{4}{|c|}{$-.35(.25)$} & \multicolumn{4}{|c|}{$-1.18(.25)$} & \multicolumn{4}{|c|}{$-.03(.25)$} \\
\hline Kurtosis (S.E.) & \multicolumn{4}{|c|}{$.46(.49)$} & \multicolumn{4}{|c|}{$2.69(.49)$} & \multicolumn{4}{|c|}{$.35(.49)$} \\
\hline Age & .60 & 3 & 90 & - & $3.09 *$ & 3 & 90 & .06 & .46 & 3 & 90 & - \\
\hline Educational Background & .89 & 4 & 88 & - & .49 & 4 & 88 & - & .68 & 4 & 88 & - \\
\hline Monthly Income & 1.94 & 4 & 19.97 & - & 1.27 & 4 & 19.46 & - & .78 & 4 & 86 & - \\
\hline Authority Experience & 1.91 & & 91 & - & -1.69 & & 91 & - & -.79 & & 91 & - \\
\hline Experience of Witnessing DV & -1.49 & & 92 & - & $\mathrm{I} .07$ & & 92 & - & -.54 & & 92 & - \\
\hline
\end{tabular}

Note: $* p<.05$

Table I also shows the results of T-test and ANOVA to explore score differences in perceived situational barriers, neighborhood cohesion, and intent to help neighbors based on demographic groups. Among all variables, significant score difference was only found in neighborhood cohesion across age groups with a medium effect size $(F(3,90)=3.09, p<.05, \omega 2=.06)$. Further post hoc test revealed that the remarkable difference was between the youngest age group (20-25 years old, $\bar{x}=63.33, \mathrm{SD}=5.92)$ and the eldest age group $(3 \mathrm{I}-40$ years old, $\bar{x}=72.09, \mathrm{SD}=10.52)$. Other than that, no notable score difference was found.

\section{Bystander Behaviors and Neighborhood Cohesion}

The result of multiple regression analysis to predict intent to help neighbors from perceived situational barriers and neighborhood cohesion is shown in Table 2. A significant regression model was found $(F(2,91)=15.57, p<.001)$ which accounted for $22 \%$ of the variation in the willingness to help DV victims. Both perceived situational barriers $(\beta=-.26, p<.01)$ and neighborhood cohesion $(\beta=.37, \mathrm{P}<.00 \mathrm{I})$ contributed significantly to respondents' intention to provide aids, with neighborhood cohesion added a little more to the prediction. Further, a correlation analysis found a small negative correlation between the two predictors $(r=-.09, p=.20)$. This correlation, however, was not significant which indicated no collinearity in the regression model. 
Table 2

Multiple Regression on Bystander Behaviour and Neighbourhood Cohesion

\begin{tabular}{lccc}
\hline \multirow{2}{*}{ Independent Variables } & \multicolumn{3}{c}{ Intent to Help Neighbours } \\
\cline { 2 - 4 } & $\mathrm{B}$ & $\mathrm{S} . \mathrm{E}$. & $\beta$ \\
\hline (Constant) & 22.30 & 6.26 & - \\
Perceived Situational Barriers & -.14 & .05 & $-.26^{*}$ \\
Neighbourhood Cohesion & .28 & .07 & $.37^{* *}$ \\
\hline
\end{tabular}

Note: $R^{2}=.22(p<.001),{ }^{*} p<.01$, **p<.001

\section{Discussion of Study I Result}

The result of the study I described male neighbors' behavior as bystanders of DV cases and its relation to perceived cohesion of the neighborhood. In general, male neighbors were found to tend to perceive relatively high situational barriers in intervening DV cases as indicated by the negative skewness, although it was insignificant. It was also the case with the respondents' willingness to help DV victims. Even though they perceived fairly high barriers, they tended to also have high level of intention to aid DV victims. This finding might seem counterintuitive, but the analysis of neighborhood cohesion could explain it.

Respondents' perceived a remarkably high perceived neighborhood cohesion as indicated by the significantly negative skewness. This finding could be explained by the fact that Indonesia is a highly collectivistic country wherein strong cohesion is one of its distinct characteristics (Hofstede et al., 2010). Based on the regression analysis, both neighborhood cohesion and perceived situational barriers predicted respondents' intention to help neighbor victims. In line with previous research (Burn, 2009), situational barriers negatively predicted male neighbors' willingness to help. However, according to the comparison of the beta coefficient, neighborhood cohesion had bigger contribution in influencing respondents' intention to intervene. It implies that although male neighbors perceived fairly high situational barriers which should have lessened their intention to intervene, they also perceived high level of neighborhood cohesion which was a stronger predictor of their willingness to help victims. Therefore, the intent to help neighbors score tended to be high.

This evidence of the role of neighborhood cohesion supports and expands the finding of an experiment by Rutkwoski and associates (1983). They found that high group cohesion could make bystanders more responsive towards emergency. Current study expanded this finding by revealing 
the role of neighborhood cohesion to promote bystander intention to help in DV cases. In addition, neighborhood cohesion was found statistically higher in eldest age group, compared to the youngest. This might be because older people had lived longer in the neighborhood which allowed them to have more social interaction in it. Degree of interaction is a facet of neighborhood cohesion (Buckner, 1988), hence the higher degree of interaction the higher the cohesion is.

\section{Result of Study 2}

All three participants in the second study were found undergoing bystander effect due to three psychological processes: diffusion of responsibility, audience inhibition, and pluralistic ignorance. All of them also had experienced situational barriers since the interpreting stage, even though they went through different dynamics.

\section{Stages of Bystander Intervention.}

\section{Noticing}

Result showed that there was no sensory distraction or any other conditions that prevented all three participants to notice the accident. Noise and scream were the stimuli that made them notice something unusual were happening at that time, for instance KD noticed the incident through a cry for help from a woman ('[I know about the accident because]At first, [I heard]there was a woman screaming 'help, help, help!...' - KD).

\section{Interpreting}

According to the result of the interview, three barriers were found: I) Pluralistic ignorance, 2) Ambiguity of the situation, and 3) Perception concerning the situation. Pluralistic ignorance was experienced by all participants. For instance, HG relied on other bystander's responses to decide whether to come out from his house and watch the DV or not ('Everyone was out at last. Watching the incident. Only then I went out... I decided to get out too. Along with my wife [to watch the incident]. If I'm alone, I feel uncomfortable [watching the incident].' - HG).

Ambiguity of the emergency cue was also found affecting $A Y$ and $H G$, although both could still recognize the situation as DV. AY was not sure about the incident because he only heard the scream of the victim without clearly seeing the scene at first. In HG's case, he heard noise from outside of his house and thought it was merely the typical clamor of his neighborhood. His 
communication with other bystander (i.e. his wife told him that the noise sounded like a woman's scream) helped him to interpret noises he heard as a cry for help from DV victim.

We also found some perception concerning the situation. First of all, all participants emphasized more on the perpetrator's characteristic as a plausible cause of the DV. Secondly, they also saw the DV they witnessed as normal and not harmful, regardless of how severe they perceived the DV was ('...Everyone already knows it [the DV] is a usual thing. It's not the first or second time he abused his wife'KD). And lastly, the three participants perceived DV as a private domestic matter ('It [DV] was actually a private domestic issue. So even if we want to help, it's confusing[how to help].'- HG).

\section{Taking Responsibility.}

In this third stage, some situational barriers were found: I) Diffusion of responsibility, 2) Bystander's relationship with the victim and perpetrator, 3) Authority figure, 4) Characteristic of the bystander, and 5) Perception and attribution towards the victim. Diffusion of responsibility was present on all participants, but towards different targets such as perpetrator's family, other bystanders at scene, and older people in the community ("I mean, the older people didn't intervene[with the DV], why should I? ... [it's] unethical' - HG).

Participants' relationship with the abuser and the victim was also found impacting the dynamics of bystander effect on KD and HG. KD had a bad affiliation with the perpetrator's relatives which made him reluctant to give any intervention, while HG perceived more personal responsibility to help the victim because he and the victim had been neighbors since long time before ('Yes [I felt responsible to help]. She[the victim] is my neighbor, right? We've known each other since long'- HG).

Concerning authority figure, KD and AY didn't think that certain people should be responsible to intervene the DV. However, AY considered chief of $R T$ as responsible to handle the DV if the case was severe enough to be brought into legal system ('If [the issue] gets bigger, well... [it should be] handled by chief of $R T$ - AY). Unlike AY, HG thought that chief of RTcould intervene the DV because it had violated the security and serenity in the neighborhood ('He [chief of RT] has the right to intervene. It's about the security... serenity of the neighborhood, right? It already caused riot' - HG).It seems like participants concerned more about maintaining the serenity of the neighborhood than ensuring the security of a single member of the community (e.g. victim of DV). 
Furthermore, the interview also revealed two characteristics of the bystander contributing in the dynamics of bystander effect, which were social role and life experience. For KD, his social role as the security staff in the neighborhood gave him a sense of need to intervene, whereas conversely HG was unwilling to help due to his role as a youth in his neighborhood ('So I'm relatively young[among other residents] ... If the older people didn't dare to intervene[the DV] ... let alone the youngster[like me]' -HG). Meanwhile, AY condemned DV-related things because of his experience of living in a violent environment which made him unwilling to be involved in such incident.

Moreover, relating to the victim, attribution of worthiness to get helped was also one of the factors impacting participants' dynamics of bystander effect. KD and HG both sympathized with the victims and didn't blame them for the abuse ('I feel sorry to see the woman [the victim] [being abused]' - KD).

\section{Decision to help.}

The result of the interviews revealed that action ignorance was present in all three participants in this fourth stage. All of them claimed that they didn't know what to do when they witnessed the abuse ('I am confused if such incident [DV] happens... even if I want to help [the victim], it's confusing' - HG). Moreover, we also found that all participants had no preference about the form of intervention they were willing to provide. This implied that they couldn't make any decision to help, much less the type of intervention to give.

\section{Providing help.}

Participants encountered three kinds of situational barriers in the fifth stage, namely: (I) Audience inhibition; (2) Perceived negative consequence of helping behavior; and (3) Contradicting social norm. All three participants were going through audience inhibition. They were anxious of getting negative response if they intervened the DV such as getting blamed for being a meddler ('We can be blamed for... uhm... meddling people's marriage issue [if we intervene with the DV]'- HG).

Meanwhile, the participants perceived plausible negative consequence of helping DV victims, which was the violation of neighborhood relation. All of them considered DV intervention as a potential cause for misunderstanding and new conflict that would in turn spoil the social bonding among neighbors ('... [If I say something about the DV] then [the relationship between] me and him 
becomes uncomfortable' - AY). Additionally, about contradicting social norm, participants regarded DV as a private matter that should never be interfered by people outside the conflicting couple ('Because DV is... a family matter. [It is a private] domestic issue'- KD). This existing norm contradicts with the norm to help someone from suffering.

\section{Neighborhood Cohesion}

According to the interview, all three participants showed fairly high neighborhood cohesion. They felt a sense of closeness with their neighborhood and considered it as a part of themselves. They also perceived communality in their environment. It indicated participants' sense of community. Based on the degree of attraction, participants showed a somewhat strong interest in the neighborhood and liked to live in it. They also indicated positive attitude towards the environment, regardless of the negative stereotypes attributed to the neighborhood as an inhospitable slum area. Furthermore, in regard of the degree of interaction, the participants didn't interact much with people in their neighborhood due to their job or their preference for spending time with their own family.

Nevertheless, the fairly strong neighborhood cohesion that the participants perceived didn't make them more willing to intervene DV cases. All three participants stated that the cohesion between neighbors in their environment didn't facilitate DV victim helping behavior, although it indeed increases helping behavior in other contexts ('[interviewer:] Despite the closeness, in term of DV, is it really difficult to intervene?'No [the closeness doesn't apply in DV cases]' - KD).In addition, the participants claimed that DV actors' (i.e. perpetrator and victim) relationship with their neighbors was one of the factors causing the absence of DV intervention by the neighbors. The participants of this research expressed that they didn't feel psychologically close to the DV actors or that the actors seldom interacted with the neighbors.

Aside from the neighborhood cohesion, the interview also inquired into criminality issues in the neighborhood. The result revealed no serious security issue present in the participants' neighborhood, even though some of them learnt about one mild criminal act or two taking place in their neighborhood such as pet theft. 


\section{Discussion of Study 2 Result}

The findings of this study described the dynamics of bystander effect experienced by male neighbors who witnessed DV. According to the situational model of helping behavior, bystander must succeed in all five stages of intervention before eventually provide assistance in an emergency. In this research, the participants were found to have experienced bystander effect and encountering situational barriers since the stage of interpreting.

Evidences about the three psychological processes underlying bystander effect were found. The first one is pluralistic ignorance which affects the way bystanders interpret DV incident. It occurs when the situation is ambiguous, such as the incidents the current study participants witness in which the only cues to notice them were ambiguous scream and noise. Ambiguous situations lead to the inaction of bystander (Latané \& Nida, 198I; Rendsvig, 20I4). Rendsvig (2014) explained that it is because individuals tend to hold themselves back from reacting to ambiguous situation and waiting for further information about it. In such situation, bystanders are also inclined to rely on others' responses in order to make sense of the situation (Fischer et al., 20l I). When bystanders observe other's passiveness toward the situation, they are likely to regard the situation as a non-emergency which needs no help (Latané \& Darley, 1968). On the other hand, communication between bystanders can help prevent this to happen (Latané \& Nida, 198I).

The second process is diffusion of responsibility. According to Darley and Latané(1968), when more than one bystanders are present, the responsibility to help will be divided to all of them. Thus, the perceived pressure to provide assistance is reduced and it results in no bystander intervention. Such situation occurred in all three cases in this study, but the participants diffused the responsibility to help to different parties. Unexpectedly, two participants did not hold authority figures responsible to intervene the DV. Further, participants tended to assume authorities' responsibility to handle the incident only when it had already inflicted social disturbance in the community, not because the DV itself was a human right violation. It seems that participants concerned more about the serenity of the neighborhood.

Bystanders' responsibility taking were also found to be affected by bystander characteristics and related with the perpetrator and the victim. Two characteristics of bystander were identified in this 
research, namely life experience and social role. Violent life experience was found hampering bystander intervention in AY case. Meanwhile, KD and HG's social role affected their respective dynamics of bystander effect differently. KD's social role (i.e. as neighborhood security staff) led him to feel more responsibility to help the victim, whereas HG's role (i.e. as neighborhood youngster) made him more reluctant instead. To understand how these two aspects of bystander's characteristic influenced this stage of intervention, both aspects needs further examination.

Likewise, participants' relation with the perpetrators and the victims also affected two participants of current study in two different ways. KD stated that he would be more willing to intervene strangers' DV than his neighbor's. His preference was relied on his belief that intervening DV by strangers could cause less plausible repercussion. Such cost evaluation of helping behavior can deleteriously impact bystander's intention to help (Suryanto et al., 20I2). Conversely, HG felt more responsible to help due to his relation with the victim as close neighbors. Suryanto and his colleagues (2012) explained that it as function of psychological distance between bystander and the victim, in which the closer the psychological distance is, the more likely bystanders will help. The fact that participants did not blame the victim for the DV could have also promoted bystander intervention. Such attribution can increase victim's deservingness for help and affect bystander's deliberation to provide assistance (Loewenstein \& Small, 2007). However, the participants of current study claimed that bad interaction between the DV actors and other community members was one reason behind bystanders' reluctance to help. Therefore, even though participants and the DV actors were neighbors, they did not feel any sense of closeness and even perceive negative possible repercussion of helping them. However, this notion should be studied further.

The last process underlying bystander effect is audience inhibition which occurred to the participants of the current study. They were worried of being judged by other bystanders if they provided aid to the victim. Hudson and Bruckman (2004) elaborated audience inhibition as a psychological process underlay by bystander's public self-awareness. In a situation where many people are present, one may think that their behaviors are observed and evaluated by people and one foolish action may give them embarrassment. Hence, the more bystanders are present, the bigger the risk of bearing embarrassment while trying to provide intervention (Darley \& Latané, 1968). This process is what can prevent bystander from helping DV victim. 
In addition to the three aforementioned psychological processes, there were some factors influencing bystander intervention of DV cases. First of all, action ignorance (i.e. bystander do not know what action they should take) was found present in all participants. It is important for bystander to know what to do in order to be able to provide intervention over a situation (Baron \& Branscombe, 2012). Even further, self-efficacy is also a critical factor influencing bystander's decision to help (Lazarus \& Signal, 2013; Suryanto et al., 2012). However, participants in current study did not know what the right and appropriate thing was to do when DV occurred and did not even believe that intervening $\mathrm{DV}$ is the right thing to do. This has some relation with their perception toward DV cases.

DV-related perceptions were indeed found to be contributing as barriers of bystander intervention. All participants perceived the perpetrators as rude and abusive and did not attribute the culpability of accident to the victim. Such attribution can increase bystanders' likelihood to provide help (Loewenstein \& Small, 2007). Participants, however, did not consider the DV as a severe, dangerous situation, despite the fact that some of them actually jittered about the possibility of the abuser to use weapon. This indicated trivialization, a state wherein bystanders do not see a situation as an emergency but as either a tolerable, non-harmful incident or a normalized, frequent scene (Thornberg, 2007). This can prevent bystander intervention because higher level of potential danger led to more likeliness for bystanders to provide aids and vice versa (Fischer, Greitemeyer, Pollozek, \& Frey, 2006).

In addition, one particular perception about DV case was consistently found in all three participants and is arguably the most critical finding of this study which indicates the norms of participants. They considered DV as a sensitive, private domestic issue, and nobody other than the couple should know. Such violence-supporting norm is actually key factor in shaping men's use of violence, tolerance for violence, as well as dearth of involvement in intervening violence (Flood, 20l Ib, $20 \mathrm{I} \mathrm{Ia).Compliance} \mathrm{with} \mathrm{such} \mathrm{contradicting} \mathrm{norms} \mathrm{could} \mathrm{result} \mathrm{in} \mathrm{audience} \mathrm{inhibition} \mathrm{and} \mathrm{bystander}$ effect (Burn, 2009; Thornberg, 2007). Frye (2007) found that bystander's belief in interpersonal partner violence as a private matter was negatively correlated to their intention to intervene.

In relation to this, participants believed that intervening DV could spoil the neighborhood relation. Such deliberation of negative consequences of helping behavior could actually prevent bystander to 
intervene a situation (Baron \& Branscombe, 20I2). Also, this may indicate that individuals from highly cohesive neighborhood tend to maintain social state. As a result, individuals will try to avoid neighborhood conflict. Of course, this will need further exploration.

In addition, this study investigated about the possibility of criminality issues in the participant's neighborhood and found no major criminality and safety issue. Gracia and Herrero (2006) stated that such criminal problems in the neighborhood is a social disorder that may hinder DV intervention because such environment with high level of danger makes the residents feel lower social control and collective efficacy which also led to high tolerance of violence. Inasmuch as we found that the participants perceived no neighborhood social disorder, we could infer that safety issue did not play significant role in preventing the participants from intervening the DV they witnessed.

\section{Discussion}

The two studies provide description about male neighbors' behavior as bystanders of DV, as well as confirm that bystander effect on DV cases occur in communities in Indonesia. Current research found relatively high perceived situational barriers, yet also fairly high intention to help. The qualitative approach of this research revealed that male witness of DV experienced bystander effect due to situational barriers which occurred starting from the stage of interpreting. Arguably, the most significant finding in this research is the role of cohesion in affecting bystander behaviors. Neighborhood cohesion better predicted male bystanders' willingness to help DV victims compared to situational barriers. Also, although insignificant, the correlation between neighborhood cohesion and situational barriers was negative in nature. This implies that higher level of cohesion tended to be accompanied by lower level of perceived barriers to help, hence higher willingness to help as well.

However, current research also found interaction between neighborhood cohesion and social norm that conflicts with DV intervention. Although cohesion was found promoting helping behavior between neighbors, its effect did not apply in DV context. This was due to an existing norm that DV is regarded as private matter and intervening such cases would spoil the good relations in the neighborhood. Compliance with such DV-supporting norms has been found preventing bystander 
behavior (Thornberg, 2007). Rutkowski and colleagues (1983) elaborated that highly cohesive group was more inclined to conform to existing group norms. Ergo, in a community with high level cohesion such as the sample pool in this research, bystanders will be more likely to comply with the conflicting norms and eventually fail to intervene DV case. This may explain as to why bystander inaction occurred in real DV cases although survey revealed that cohesion could make male neighbors more willing to help. It is also possible that members of highly cohesive neighborhood tended to maintain social status-quo which may explain their emphasis of DV as a threat for neighborhood harmony rather than DV as a human right violation

This research provided evidence of situational factors and the presence of other bystanders hampering DV intervention as proposed by situational model (Darley \& Latané, 1968) and the theory of social impact (Latané, 198I). It also proved that the reason of bystander inaction occurred was contextualized. Male participants were silent not solely due to situational barriers or the effect of other figure presence in DV cases, but the inaction was also rooted in distorted social norm and personal value about DV. This is similar to Levine's (1999) notion that inaction is not only a product of apathy or reliance to other, but also due to distortion of social categorical relationship as well as norms and value associated with intervention. This research is also in line with Banyard and associates' $(2007,2004)$ findings that correction of bystander effect or bystander inaction should focus on reshaping belief and attitude pertaining to DV.

There is however limitation to this research regarding its data collection. Respondent and participants of this research seemed to have little interest, furtive, and defensive about the topic, despite the fairly long duration of rapport building. This fact is in line with Katz's (2006) elaboration that men are inclined to avoid talking about violence against women. The nature of this research might also make the subjects defensive because they did not want to seem ignorant toward their neighbors as it contradicts with their sense of neighborhood cohesion. Therefore, future research should consider other methods to collect data in order to increase subject's willingness to participate in similar research.

Despite its limitation, the findings of this research have implications for intervention of DV cases in Indonesia. Indonesian government should design a community-based intervention program, especially for men, which focuses on shaping new norm and attitude which support DV intervention, 
increasing knowledge on how to intervene DV cases, and building men's openness to topics around DV and awareness of their role DV elimination endeavor as well.

\section{Conclusion}

This research had succeeded in exploring bystander behavior, its relation to neighborhood cohesion, and the dynamics of bystander effect on male neighbors who witnessed DV. The findings provided evidences which expanded Latané's (198I) theory of social impact, Darley and Latané's (1968) situational model, and Rutkwoski and colleagues' (1983) study about the role of cohesion in helping behavior, as well as supporting Levine's (1999) notion and Banyard and colleagues'(2004) findings pertaining to distorted norms as a root of bystander inaction. Bystander inaction was found to occur because of situational barriers and the interaction between social norms and neighborhood cohesion. The function of neighborhood cohesion to promote helping behavior is hampered, if not reversed, by DV-supporting norm. These findings are potential to be the focus of social intervention of DV cases in Indonesia. By eliminating or minimizing the factors which heighten the likeliness of bystander effect occurrence and taking advantage of high cohesion in the community as potential promoter of bystander intervention, we may increase the participation of the community as active bystanders in the endeavor to eradicate DV cases. Future studies can focus on investigating relationship between life experience and social role with bystander's intention to help, exploring the tendency of a cohesive neighborhood to sustain its social stability which may inhibit prosocial behavior in DV cases, and mapping DV-related attitude in Indonesian community to ensure whether bystander's attitude and norm identified in this research are cultural or merely occurring in the pool of participant. Further exploration on these subjects can contribute to better understanding on bystander behavior in term of DV case, especially in Indonesia. This research, however, has a limitation in term of the data collection process where participants seemed to be fairly resistant to the research topic. As it may raise concern regarding the data reliability, future studies should find other methods to increase participant's willingness to participate in similar research. 


\section{References}

Banyard, V. L., Moynihan, M. M., Cares, A. C., \& Warner, R. (20I4). How do we know if it works? Measuring outcomes in bystander-focused abuse prevention on campuses. Psychology of Violence, 4(I), I0I-I I5. https://doi.org/I0.1037/a0033470

Banyard, V. L., Moynihan, M. M., \& Plante, E. G. (2007). Sexual violence prevention through bystander education: An experimental evaluation. Journal of Community Psychology, 35(4), 46348I. https://doi.org//0.1002/jcop.20159

Banyard, V. L., Plante, E. G., \& Moynihan, M. M. (2004). Bystander education: Bringing a broader community perspective to sexual violence prevention. Journal of Community Psychology, 32(I), 6I-79. https://doi.org//0.1002/jcop. 10078

Baron, R. A., \& Branscombe, N. R. (20I2). Social Psychology (I3th ed.). USA: Pearson.

Berk, R. A., Berk, S. F., Newton, P. J., \& Loseke, D. R. (1984). Cops on call: summoning the police to the scene of spousal violence. Law \& Society Review, I8(3), 479-498. https://doi.org/I 0.3366/ajicl.20I I.0005

Buckner, J. C. (1988). The development of an instrument to measure neighbourhood cohesion. American Journal of Community Psychology, I6(6), 77I-79I. https://doi.org//0.1007/bf00930892

Burn, S. M. (2009). A situational model of sexual assault prevention through bystander intervention. Sex Roles, 60(I I-12), 779-792. https://doi.org/I 0.1007/s I I 199-008-958I-5

Chabot, H. F., Tracy, T. L., Manning, C. a, \& Poisson, C. a. (2009). Sex, Attribution, and Severity Influence Intervention Decisions of Informal Helpers in Domestic Violence. Journal of Interpersonal Violence, 24(I0), I696-I7I3. https://doi.org/I0.I I77/088626050933 I5I4

Cismaru, M., Jensen, G., \& Lavack, A. M. (2010). If the Noise Coming from Next Door were Loud Music, You'd Do Something About It. Journal of Advertising, 39(4), 69-82. https://doi.org//0.2753/JOA009I-3367390405

Darley, J. M., \& Latané, B. (1968). Bystander Intervention in Emergencies: Diffusion of Responsibility. Journal of Personality and Social Psychology, 8(4 PART I), 377-383. https://doi.org// 0.1037/h0025589

Fischer, P., Greitemeyer, T., Pollozek, F., \& Frey, D. (2006). The unresponsive bystander: Are bystanders more responsive in dangerous emergencies? European Journal of Social Psychology, 36(2), 267-278. https://doi.org//0.1002/ejsp.297

Fischer, P., Krueger, J. I., Greitemeyer, T., Vogrincic, C., Kastenmüller, A., Frey, D., ... Kainbacher, M. (20II). The bystander-effect: A meta-analytic review on bystander intervention in dangerous and non-dangerous emergencies. Psychological Bulletin, 137(4), 517-537. https://doi.org//0.1037/a0023304

Flood, M. (20l la). Building men's commitment to ending sexual violence against women. Feminism and Psychology, 2 I (2), 262-267. https://doi.org/I0.I I77/09593535I 0397646

Flood, M. (20l lb). Involving men in efforts to end violence against women. Men and Masculinities, 
14(3), 358-377. https://doi.org//0.1 177/1097/84X10363995

Frye, V. (2007). The informal social control of intimate partner violence against women: Exploring personal ahitudes and perceived neighborhood social cohesion. Journal of Community Psychology, 35(8), I00I-1018. https://doi.org/I0.1002/jcop.20209

Garcia, S. M., Weaver, K., Moskowitz, G. B., \& Darley, J. M. (2002). Crowded minds: The implicit bystander effect. Journal of Personality and Social Psychology, 83(4), 843-853. https://doi.org//0.1037/0022-35|4.83.4.843

Gracia, E., García, F., \& Lila, M. (2009). Public responses to intimate partner violence against women: the influence of perceived severity and personal responsibility. The Spanish Journal of Psychology, I2(2), 648-656. https://doi.org//0.1/77//07780I2083 I7288

Gracia, E., \& Herrero, J. (2006). Public attitudes toward reporting partner violence against women and reporting behavior. Journal of Marriage and Family, 68(3), 759-768.

https://doi.org//0.1 I I I/j. I74I-3737.2006.00288.x

Hoefnagels, C., \& Zwikker, M. (200I). The Bystander Dilemma and Child Abuse: Extending the Latane and Darley Model to Domestic Violencel. Journal of Applied Social Psychology, 3 I (6), I I58-I I83. https://doi.org/I0.I I I I/j.I559-|8|6.200I.tb02668.x

Hofstede, G., Hofstede, G. J., \& Minkov, M. (2010). Cultures and Organizations: Software of the Mind: Intercultural Cooperation and Its Importance for Survival (3rd ed.). New York: McGraw Hill.

Hudson, J. M., \& Bruckman, A. S. (2004). The Bystander Effect: A Lens for Understanding Patterns of Participation. Journal of the Learning Sciences, 13(2), 165-195.

https://doi.org// 0.1207/s I 5327809jls I 302_2

Katz, J. (2006). The Macho Paradox: Why Some Men Hurt Women and How All Men Can Help. Illinois: Sourcebook, Inc.

Kimmel, M. S. (2002). "Gender symmetry" in domestic violence: A substantive and methodological research review. Violence Against Woman, 8(II), I332-1363.

https://doi.org//0.1 I77/107780102237407

Langhinrichsen-Rohling, J., Foubert, J. D., Brasfield, H. M., Hill, B., \& Shelley-Tremblay, S. (20I I). The men's program: Does it impact college men's self-reported bystander efficacy and willingness to intervene? Violence Against Women, $17(6), 743-759$.

https://doi.org/I0.1 I77/I07780I2II409728

Latané, B. (198I). The psychology of social impact. American Psychologist, 36(4), 343-356. https://doi.org// 0.1037/0003-066X.36.4.343

Latané, B., \& Darley, J. M. (1968). Group Inhibition of Bystander Intervention in Emergencies. Journal of Personality and Social Psychology, 10(3), 215-221.

Latané, B., \& Nida, S. (198I). Ten years of research on group size and helping. Psychological Bulletin, 89(2), 308-324. https://doi.org//0.1037/0033-2909.89.2.308

Lazarus, K., \& Signal, T. (20I3). Who will Help in Situations of Intimate Partner Violence $\square$ :

Exploring Personal Attitudes and Bystander Behaviours. International Journal of Criminology and 
Sociology, 2(2004), 199-209.

Levine, M. (1999). Rethinking Bystander Nonintervention: Social Categorization and the Evidence of Witnesses at the James Bulger Murder Trial. Human Relations, 52(9), II 33-II 55. https://doi.org/I0.1023/A:101699/826572

Levy, I., \& Ben-David, S. (20I5). Mechanism of bystander-blaming: Defensive attribution, counterfactual thinking, and gender. International Journal of Offender Therapy and Comparative Criminology, 59(I), 96-II3. https://doi.org/I0.II77/0306624XI3503297

Loewenstein, G., \& Small, D. A. (2007). The Scarecrow and the Tin Man: The vicissitudes of human sympathy and caring. Review of General Psychology, I I (2), I I 2-126. https://doi.org/I0.1037/I089-2680.1 I.2.112

Margaretha, M., Nuringtyas, R., \& Rachim, R. (20I3). Childhood Trauma of Domestic Violence and Violence in Further Intimate Relationship. Makara Human Behavior Studies in Asia, I 7(I), 33. https://doi.org/l0.7454/mssh.vI7il.I800

McQuigg, R. J. A. (20I I). International human rights law and domestic violence $\square$ : the effectiveness of international human rights law. Abingdon: Routledge.

National Commission on Violence against Women. (2016). "Kekerasan terhadap Perempuan Meluas: Medesak Negara hadir Hentikan Kekerasan Terhadap Perempuan di Ranah Dimestik, Komunitas dan Negara.”Jakarta. Retrieved from https://www.komnasperempuan.go.id/file/pdf_file/Catatan Tahunan/I4.PP5_CATAHU 2016.pdf

National Commission on Violence against Women. (2017). Labirin Kekerasan terhadap Perempuan: Dari Gang Rape hingga Femicide, Alarm bagi Negara untuk Bertindak Tepat. Jakarta. Retrieved from https://drive.google.com/file/d/OBwSyakH_8_nRkRNTVBxX0Q I aWs/view? usp=sharing

Patton, M. Q. (2002). Qualitative Research \& Evaluation Methods (3rd ed.). London: SAGE Publication.

Rendsvig, R. K. (20I4). Pluralistic ignorance in the bystander effect: informational dynamics of unresponsive witnesses in situations calling for intervention. Synthese, 19I(II), 247I-2498. https://doi.org/I0.1007/s I I 229-0 I4-0435-0

Rich, M. D., Utley, E. A., Janke, K., \& Moldoveanu, M. (2010). "l'd Rather Be Doing Something Else:" Male Resistance to Rape Prevention Programs. The Journal of Men's Studies, 18(3), 268-288. https://doi.org/I0.3149/jms. I803.268

Rutkowski, G. K., Gruder, C. L., \& Romer, D. (1983). Group cohesiveness, social norms, and bystander intervention. Journal of Personality and Social Psychology, 44(3), 545-552. https://doi.org//0.1037/0022-35/4.44.3.545

Schwartz, M. D., \& DeKeseredy, W. S. (2008). Interpersonal Violence Against Women. Journal of Contemporary Criminal Justice, 24(2), I 78-185. https://doi.org/ I0. I I 77// 0439862083 I 5483

Suryanto, Putra, M. G. B. A., Herdiana, I., \& Alfian, I. N. (20I2). Pengantar Psikologi Sosial. Surabaya: Airlangga University Press.

Thornberg, R. (2007). A classmate in distress: Schoolchildren as bystanders and their reasons for how they act. Social Psychology of Education, I0(I), 5-28. https://doi.org// 0.1007/s I I 2 I8-006- 
$9009-4$

Tice, D. M., \& Baumeister, R. F. (1985). Masculinity inhibits helping in emergencies: Personality does predict the bystander effect. Journal of Personality and Social Psychology, 49(2), 420-428. https://doi.org//0.1037/0022-35/4.49.2.420

Walker, L. E. (1999). Psychology and Domestic Violence. American Journal of Psychology, 54(I), 2I-29.

World Health Organization. (20I3). Global and regional estimates of violence against women: prevalence and health effects of intimate partner violence and non-partner sexual violence. 20/3, 57. https://doi.org//0.1007/s |3398-014-0173-7.2

Xu, Q., \& Anderson, A. (2010). Domestic Violence in Asian Cultures. In L. E. Ross (Ed.), The War Against Domestic Violence (pp. 27-40). Boca Raton: CRC Press. 